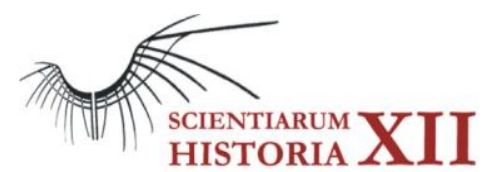

The subject Da Vinci and his scientist becoming

\title{
O sujeito Da Vinci e seu devir cientista
}

\author{
Karine Xavier Cavalcante Ferreira ${ }^{1}$ \\ ${ }^{1}$ Doutoranda do Programa de Pós-Graduação em Filosofia- UFRJ e Mestre pelo \\ Programa de Pós-Graduação em Teoria Psicanalítica- UFRJ
}

Recebido: 4/12/2019 Aceito: 8/12/2019 Publicado: 12/12/2019

karineferreirapsi@outlook.com

\begin{abstract}
Leonardo da Vinci is evoked in the literature of the scientific thought by the originality and plurality of his works, and his legacy gives us news of the relationship between the researcher and his research objects. Representing the brightest minds of the Renaissance, Da Vinci drives his biographers and all those interested to the moment of transition of scientific occidental thinking between the low middle age and the modern age. It is through the Koyrerian perspective of this transition that we will emphasize his scientist becoming, valuing him as the subject of measurement, calculation, accuracy, and his uncanniness, elements that expose him at the forefront of a new language in the field of knowledge.
\end{abstract}

Keywords: Renaissence. Epistemology. Alexandre Koyré.

Resumo. Leonardo da Vinci é evocado na literatura do pensamento científico pela originalidade e pluralidade de suas obras, seu legado nos dá notícias da relação inquieta entre o pesquisador e seus objetos de pesquisa. Representante das mentes mais brilhantes do Renascimento, Da Vinci conduz seus biógrafos e todos os interessados ao momento de transição do pensamento científico entre a baixa idade média e a idade moderna. Será através da perspectiva koyreriana desta transição ocidental que daremos destaque ao seu devir cientista, valorizando-o como sujeito da medida, do cálculo, da exatidão, e de sua inquietude, elementos que o expõe na vanguarda de uma nova linguagem no campo do saber.

Palavras-chave: Renascença. Epistemologia. Alexandre Koyré.

\section{Sujeito inquieto}

"Diga-me", "diga-me", a expressão é frequente em seus escritos (Riaño, 2019), uma demanda localizada no exercício de sua autorreflexão, que nos dá notícias do seu inquieto movimento de investigação, assim como da distância entre ele e o "outro" a quem é demanda a verdade. 
Da Vinci escreve em segunda pessoa, a partir desta distância, por e para um saber que lhe falta. Inquieto, ele nos oferece o testemunho de sua experiência sensível e forja um saber sobre a referida condição. Concernente à sua experiência, Bramly (1989, p. 103) cita a seguinte frase de Da Vinci: "quanto maior a sensibilidade, maior o martírio - um grande martírio" (apud Siqueira, 2005, p.5).

A breve análise destes dois fragmentos da escrita de Da Vinci converge ao que é experimentado na contemplação de suas obras, o que o expõe inquietante (Freud, 2010) e à frente dos novos paradigmas para o exercício da ciência, ora estranho, ora familiar à escolástica vigente.

A ambiguidade é possível de ser apreciada em suas obras, quando ele engenhosamente forja um sorriso misterioso em seus personagens andrógenos, frequentes em pinturas e esboços inacabados, cuja estética resulta da mistura de temas clássicos com motivos cristãos (Figura 1).

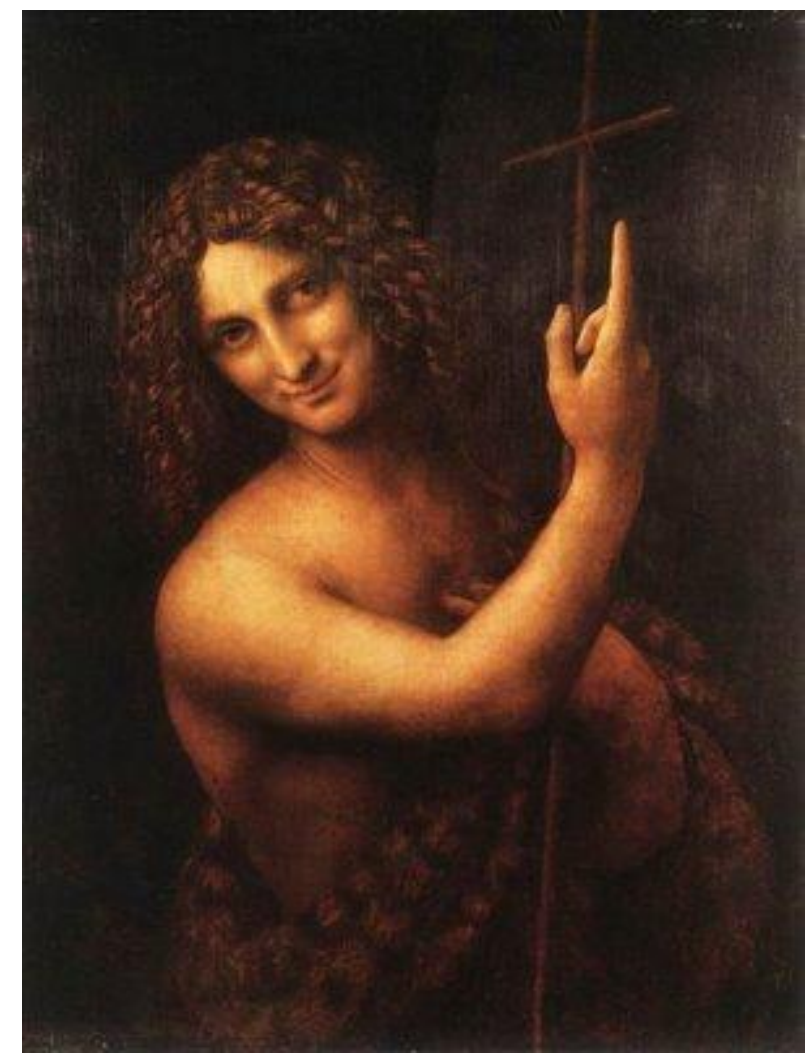

Figura 1. São João Batista. Leonardo da Vinci, 1515.

Fonte: www.culturagenial.com 
É característica do homem renascentista o resgate da cultura e estética grega, objetivando um olhar crítico à ciência aristotélica, aos pilares fundamentais da teorização e difusão do conhecimento escolástico.

Assim, a práxis deste sujeito transborda os muros dos monastérios, mas não devolve seu espírito às origens gregas que ele revisita, localizando-o no lugar Outro de sua escrita. Para compreender este lugar e o que ele traz de novidade ao pensamento moderno, evocamos Alexandre Koyré.

\section{Verdade e destino}

Koyré foi um filósofo francês, de origem Russa, e que dedicou sua obra ao estudo da história e do pensamento científico ocidental. $\mathrm{O}$ autor parte de que a revolução científica do séc. XVII foi uma revolução teórica, crítica à razão aristotélica e platônica, o que não derroga a condição de ciência do trabalho de teorização e investigação do mundo, feitas até então (Koyré, 1982).

O motor da revolução não se resume aos avanços técnicos de observação e experiência direta do pesquisador. As descobertas conquistadas com a utilização do telescópio de Galileu não são o ponto de partida da nova ciência, mas consequência da nova linguagem científica que se constituiu com a matematização da realidade. Ela possibilitou a construção do telescópio e sua condição de ser, não apenas como uma ferramenta, mas como um instrumento científico, na pertinência de sua utilização e na interpretação de seus resultados (Barbosa, 2011, p.9).

A geometrização do espaço possibilita ao cientista outra experiência com o real, além de sua experiência sensível. A quebra da divisão hierárquica do cosmos entre a realidade terrestre e celeste não seria possível sem este real geometrizado, e o devir de um indivíduo, em sua unidade geometricamente localizada no universo também não seria (Figura 2).

O destino deste sujeito diante do infinito não parece confortável, mas inquietante. Pensá-lo a partir deste universo não dispensa o que, para Koyré (1948) fundamenta a nova ciência, desde o desenvolvimento de seus instrumentos: A medida, o cálculo e a exatidão.

Coisa curiosa: dois mil anos antes, Pitágoras havia proclamado que o número é a própria essência das coisas: e a Bíblia havia ensinado que Deus fundara o mundo sobre "o número, o peso, a medida". Todos repetiram - mas ninguém acreditou. Pelo menos, até Galileu, ninguém levou a sério. (Koyré, 1948, p. 277).

Contudo, não estariam estes elementos no horizonte das obras de Da Vinci? 


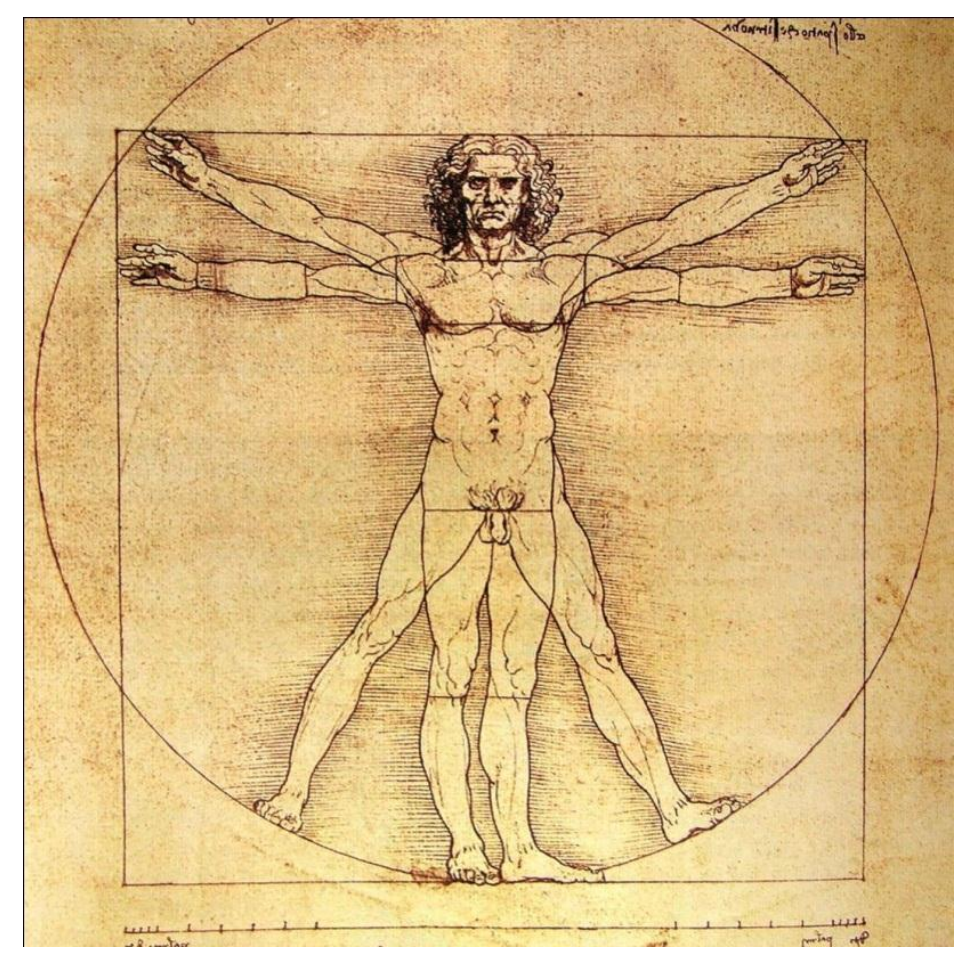

Figura 2. O Homem Vitruviano. Leonardo da Vinci, 1490.

Fonte: www.culturagenial.com

\section{3. $O$ cientista e a verdade}

Ao passo que ele se localiza, e só o faz a partir de uma escrita cuja perspectiva é matematizada, o sujeito da ciência é implicado na distância entre ele e a verdade de seu objeto de estudo. A verdade não é garantida por revelações divinas, mas está para sempre no horizonte, o que o impulsiona à investigação e evoca fantasias sobre sua origem perdida (Freud, 2010, p.104).

É possível sustentar que o cientista está, pois, entre o que, destas fantasias lhe é consciente e o que delas ele não sabe. Esta é também uma condição ambígua para aquele que, diante de uma perspectiva proposicional do espaço, o descreve de um lugar não todo, por uma condição dividida, causa de seu devir.

O homem renascentista é herdeiro da cultura com a qual ele atribui a sua origem, a origem da cultura ocidental, e dela, ele não é todo coincidente nem consciente. Através deste movimento de repetição e elaboração, ele não chega a um ponto zero da sua origem, não fecha a questão, não cessa de buscar a verdade originária.

E veremos como é pela repetição, como repetição de decepção, que Freud coordena a experiência, enquanto que decepcionante, com um real que será daí por diante, no campo da ciência, situado como aquilo que o sujeito está condenado a ter em falta mas que essa falta mesmo revela. (Lacan, 2008, p. 45) 
A partir do exposto, o cientista moderno se parece com o mito de Édipo Rei, no instante anterior à descoberta da verdade sobre o seu desejo, mas, diferente da realização de Édipo, ele se mantém neste instante e trabalha com ele, sempre querendo saber mais.

O trabalho de Da Vinci expõe tal condição de ser, e a transmite na incompletude de seus esboços, na sua demanda de saber e no enigma de seus sorrisos. Trata-se, portanto, de um sujeito diante do próprio devir, não todo consciente de seu passado, de seu objeto de estudo, da mais íntima e "martiriosa" fantasia que vela a verdade, verdade que move seu desejo de saber, 118 anos à frente do cogito cartesiano (Penso, logo existo).

Podemos apostar que, quando se perguntava em segunda pessoa, Da Vinci apontava para um lugar possível ao homem no universo matematizado, e quando perguntava "diga-me", também autenticava seu devir no momento em que pensava sobre o seu pensamento.

\section{Considerações}

Precisar o momento exato do ato fundador do cientista é uma tarefa difícil, visto que não temos mais do que seu herdeiro, coincidente à sua origem, ausente no momento de sua reprodução, circunscrevendo-a no seu a posteriori. Em todo caso, implicamos Da Vinci no berço deste processo, pela forma como nele o desejo de saber se destacou, e também nos implicamos como a condição do devir cientista, na disposição de investigalo.

Quando consideramos a originalidade de suas obras nos inspiramos e nos aproximamos dele como sujeitos de nosso desejo de saber, e sujeitos ao que, da verdade do desejo, nós não sabemos.

O processo de investigação envolve o cientista na busca pela verdade que, quanto mais perseguida, mais descrita, mais se faz presente de modo inverso ao que se espera, ou seja, ela está sempre presente, sob a sombra das palavras não ditas, das retas e números foracluídos.

Se o homem anatomofisiológico de Da Vinci existe através de esboços inacabados, ele espelha a inquietação que sustenta o pensamento científico. Os herdeiros de seu legado também são sujeitos da ciência, destinados à produção do conhecimento, à reprodução de sua insatisfação e à distância entre ele e a verdade de sua origem.

A condição faltosa do cientista e o modo como ela possibilitou transformações no pensamento moderno não derroga o lugar do homem diante dos mistérios divinos, mas o mantém paralelo a Deus e ao Estado, numa relação estranha e familiar com os mesmos, contribuindo para uma práxis audaz, ao longo de seis séculos. 


\section{Financiamento}

O presente trabalho foi realizado com apoio da Coordenação de Aperfeiçoamento de Pessoal de Nível Superior - Brasil (CAPES) - Código de Financiamento 001.

\section{Referências}

BARBOSA, M.R. Alexandre Koyré e a Revolução Científica do século XVII: formulação de um novo conceito para a ciência experimental. Livro de anais do XXVI Simpósio Nacional de História. ANPUH. São Paulo, p. 1-14, julho 2011. Disponível em:

http://www.snh2011.anpuh.org/resources/anais/14/1300848607_ARQUIVO_Comunica caoANPUH.pdf>. Acessado em 10/02/2020.

CUNHA, Sónia. Leonardo da Vinci: 11 obras fundamentais. 2017. Disponível em: $<$ https://www.culturagenial.com/obras-de-leonardo-da-vinci/ $>$ Acessado em $10 / 02 / 2020$.

FREUD, S. Uma Recordação da infância de Leonardo Da Vinci. Observações sobre um caso de neurose obsessiva ("O homem dos ratos"), Uma Recordação da infância de Leonardo da Vinci e outros textos [1909-1910]. 1 ed. São Paulo: Companhia das Letras, 2010.

O inquietante In: História de uma neurose infantil ["o homem dos Lobos"], Além do princípio do prazer e outros textos [1917-1920]. 1 ed. São Paulo: Companhia das Letras, 2010.

KOYRÉ, A. Estudos de História do Pensamento Científico. Rio de Janeiro. Forense Universitária. Brasília: Ed. UnB, 1982.

Do mundo mais-ou-menos ao universo da precisão. Critique. $\mathrm{n}^{\circ}$ 28, p. 271-288, setembro 1948. Disponível em: < http://www.unirio.br/cch/filosofia/Members/ecio.pisetta/Biblio.Koyre.Do\%20mundo $\% 2$ 0do\%20mais\%20ou\%20menos....pdf/at download/file>. Acessado em 10/02/2020.

LACAN, J. O Seminário, livro 11: Os quatro conceitos fundamentais da psicanálise. 2 ed. Rio de Janeiro: Jorge Zahar, 2008.

RIAÑO, P.H. Leonardo da Vinci: cinco séculos de uma obsessão. Jornal El País, Madrid. 12019.2 maio Disponível em: <https://brasil.elpais.com/brasil/2019/05/01/internacional/1556722757_181622>.

Acessado em 10/02/2020.

SIQUEIRA, B.E.F. Leonardo da Vinci: fantasma, arte e sublimação. Revista Psicanálise e Barroco. 3 ed. $\mathrm{n}^{\mathrm{o}}$ 1, p. 1-10, 2005. Disponível em: $\langle$ http://www.psicanaliseebarroco.pro.br/revista/revista-v-03-n-01 $>$. Acessado em $10 / 02 / 2020$. 